\title{
Saudi EFL Students' Personality Types and Their Language Learning Strategies
}

\author{
Hanan K, Al-Dail \\ Localization and Translation Manager, The Saudi Authority for Accredited valuers \\ E-mail: hanandayle@gmail.com
}

Nasser M, Freahat (Corresponding author)

Faculty of Languages and Translation, Imam Mohammad Ibn Saud Islamic University

E-mail: nmfreahat@imamu.edu.sa

Received: May 5, 2019 Accepted: May 27, 2019 Published: May 30, 2019

doi:10.5296/jsel.v7i1.14871 URL: https://doi.org/10.5296/jsel.v7i1.14871

\begin{abstract}
The purpose of this study was to examine the relationship between personality types and English language learning strategies, and to examine the pattern of English language learning strategies used by Saudi EFL university students. The sample of the study consisted of 68 EFL female students in the English department at Al-Imam Muhammad Ibn Saud Islamic University (IMSIU). Two instruments were used to collect the data; Oxford's (1990) Strategy Inventory for Language Learning (SILL) and the Myers-Briggs Type Indicator (MBTI). The findings indicated that the participants were medium-high range strategy users and that the most frequently used strategy category among the six categories is metacognitive strategies followed by cognitive strategies, compensation strategies, social strategies, memory strategies, and finally, affective strategies. The observations indicated that there were some significant differences among students' language learning strategy preferences based on their personality type. However, the relationship between the two variables is more complex and by no means direct and the reason was discussed in the research.
\end{abstract}

Keywords: Personality Types, Language Learning Strategies 


\section{Introduction}

There has been an increase in the focus on the psychology of the learner and language learner characteristics in recent research. This trend started with the studies emphasizing on the characteristics of good language learners (Johnson, 1999; Naiman, 1978; Norton \& Toohey, 2001; Rubin, 1975). Researchers found that identifying the strategies used by good language learners is a good way to make learners aware of the significance of language learning strategies. Researchers also noticed that individual differences play a crucial role in second language acquisition. This interest proposes studying the effect of individual differences on second language acquisition. Despite the interest of the study of individual differences, the relationship between personality type and language learning strategies has not flourished until the late 1980s. Ellis proposed that this is due "the lack of testing instruments that can reliably measure different types" (1985, p.12). After the emergence of the Myers-Briggs Type Indicator (MBTI), this difficulty has been overcome. Nevertheless, Dornyei (2005) notes that personality studies on the second language (L2) are still considered minimal compared to other individual differences and there is plenty of room for development. This research aims to illustrate the correlation between personality type and language learning strategies (LLSs) in a Saudi University context in order to increase awareness of such relationship and provide teachers with profound insight on how to deal with individual differences.

\subsection{Statement of the Problem}

Although studies on individual differences and second language learning strategies are numerous and extensive, there is still lack of research in some aspects of individual differences, namely personality. This lack of research is even more evident in Saudi context or Arabic EFL learners in general. The researchers $\backslash$ believe that investigating the relationship between personality and language learning strategies may increase the autonomy of language learners, raise the awareness of language learning processes and encourage the control of their own learning.

\subsection{Purpose of the Study}

The primary purpose of the study is to investigate the correlation between personality types and language learning strategies for female English major students in Al-Imam Muhammad Ibn Saud Islamic University (IMSIU). More specifically, this study seeks to answer the following research questions:

1. What is the general pattern of English language learning strategies used by Saudi EFL students?

2. Is there any significant relationship between Saudi EFL students' language learning strategies and their personality types?

\subsection{Significance of the Study}

The significance of the study lies in the information it provides concerning the relationship between the learners' personality types, language learning strategies and their proposed effect on English learning. This study may bring to light the neglected aspects of individual needs 
and personality differences in traditional learning. Teachers can obtain a complete understanding of their students' learning strategies preferences as well as the traits of their personality type. This research also increases both teachers and students' awareness of how personality types may influence the use of language learning strategies. It also provides a better understanding of how these factors will influence students' learning performance. The study will probably enable students to become more aware of their own preferred language learning strategies, and may help them chose the easiest, most suitable way to direct their own learning. In addition, the findings and recommendations may attract the attention of other researchers to investigate the process of language learning as well as learner differences in language learning in Saudi Arabia.

\subsection{Limitations}

There are some limitations in the study which include:

1. Data collection was limited to Al-Imam Muhammad Ibn Saud Islamic University in Riyadh.

2. The data of this study is limited to female students.

3. Personality type data was limited to results obtained from the Myers-Briggs Type Indicator (MBTI).

4. Language learning strategies were gathered through the Strategy Inventory for Language Learning (SILL).

\section{Literature Review}

Research on personality and language learning emerged in studies on the notion of the good language learner such as the works of Rubin (1975) and Stern (1975) which list the successful strategies that good language learners use when learning the language. This was followed by further research (Ellis, 1994; Oxford, 1990; O’Malley et al, 1985) which moved later on into the meaning of language learning strategy. However, the study on personality in relation to language learning strategies is still an underdeveloped area of research (Dornyei, 2005).

Although there is research that support the idea that personality factors have a significant influence on the degree of achievement in second language learning this might be based on the assumption that some characteristics of the learner's personality might encourage or impede learning a second language (Cook, 2001). This could be dealt with by enhancing certain aspects of language learning while preventing other unwanted aspects. Generally, studies that investigate the relationships among personality, second language learning, and achievement have produced conflicting results (Dornyei, 2005).

Literature suggests that these conflicted results may stem from researchers' lack of interest in considering personality as an independent factor in the process of second language learning. This might be caused by linguists' focus on second language learning while psychologists 
research centered around first language learning processes (Pica, 2003). This led to the separation of this multidisciplinary topic to the fields of psychology, linguistics, and education. As a result, each field efforts remain disintegrated and only partially informed. Another possible reason for these conflicted results is due to the wide variation of methodologies and instruments used to test the relationship between personality and language achievement. Therefore, Dornyei (2005) proposes to shift the research focus to study the relationship between personality type and language learning strategies instead of academic achievement.

\subsection{Language Learning Strategies}

Research on language learning strategies has focused on describing strategies employed by successful second language learners (O’Malley et el, 1985). Primarily, good language learners utilize more and better learning strategies than poor language learners (Oxford, 1989). O'Malley and Chamot (1990) proposed that successful language learners use suitable learning strategies more than less successful learners in second language acquisition. There are various definitions and classifications of strategies, and there is some uncertainty over the distinction between general learning strategies and language-specific learning strategies. Rubin (1975) defines strategies as "the techniques or devices which a learner may use to acquire knowledge" (p.43). Chamot (2001) shares a similar definition "techniques or procedures that facilitate a learning task." (p.25). Cohen (1998) defines strategies as "learning processes which are consciously selected by the learner" (p.4)". Oxford (1999) developed a more comprehensive definition "Specific actions, behaviors, steps or techniques that students use to improve their own progress in the developing skills in a second or foreign language. These strategies can facilitate the internalization, storage, retrieval or use of the new language"(p.518).

Many researchers suggested their taxonomies of language learning strategies according to their research findings. However, most classifications reflect relatively similar categories of language learning strategies without any major changes. O'Malley \& Chamot (1985) grouped the language learning strategies into three categories: metacognitive strategies, cognitive strategies, and socioaffective strategies. Rubin (1995) made a distinction between strategies contributing directly to learning and those contributing indirectly to learning. According to Rubin, there are three types of strategies used by learners that contribute directly or indirectly to language learning. These are (1) Learning Strategies, (2) Communication Strategies, and (3) Social Strategies. Oxford's (1990) divided language learning strategies into two main categories, direct and indirect strategies which are also subdivided into six classes. The strategy inventory for language learning consists of Cognitive, Memory, Compensatory, Metacognitive, Affective and Social strategies. The first three strategies being direct strategies and the later three are indirect. For the purpose of this study, this classification will be adopted, thus further information on each category will be discussed.

\subsection{Research on Language Learning Strategies and Learner's Personality Type}

Language learning strategies and learning styles have recently been one of the major fields of research in language learning and language acquisition. The majority of related studies 
focused on strategy use. However, the focus on personality as one of the language learning variables was not very common. Furthermore, very few studies have tackled the correlation between language learning strategies and the personality type. As far as the researchers are concerned, this is the first study that investigates the correlation between language learning strategies and the personality type of Saudi students. Below is a review of related studies.

Peal (1994) investigated if any of Oxford strategy groups were particularly helpful to anyone of the MBTI types in either formal or informal language learning contexts. The results were significant. In formal contexts, social strategies and cognitive strategies were particularly helpful to MBTI Feeling type. As for informal contexts, cognitive strategies were helpful to MBTI intuition type and social strategies are helpful to MBTI intuition and judging types.

Chen (2005) administered three survey instruments, Myers-Briggs Type Indicator (MBTI), Perceptual Learning Preferences Survey (PLPS), and Strategy Inventory for Language Learning (SILL) to Taiwan senior high school students learning English as a foreign language. The findings revealed that differences among students' language learning strategy preferences were based on their personality type. The findings are in line with those reported by Ehrman and Oxford's (1989) study. As the case with Ehrman and Oxford (1989), those with an extroverted personality type were more likely than introverts to use affective strategies. Furthermore, the researcher found that intuitive type students used more social strategies than sensing type students. Chen (2005) suggested the replication of this study worldwide. This would help identify whether or not differences exist across cultures and nationalities.

Riazi (2007) investigated language learning strategy use among 120 female students majoring in English at a university in Qatar. Perceptions of strategy use were measured by the Strategy Inventory for Language Learning. The study found that EFL learners featured medium bordering on high strategy users. It also found that strategy categories were used in the order of metacognitive, cognitive, compensation, social, memory, and affective; (3) freshmen students reported the highest rate of strategy use.

Shirley (2007) explored the topic in a psychological perspective. The participants in the study consisted of military students who were studying Modern Standard Arabic at the Defense Language Institute. The research resulted in a significant relationship between personality and second language learning at the facet level of measurement. The findings suggest the need to develop a multidisciplinary research approach to examine the relationship between personality and second language learning. Especially, a collaborative effort between psychologists, second language researchers, and language educators to develop adequate theoretical guidance and psychometrically derived instrumentation that provides a more clear view on the relationship between personality and second language learning. Indeed such concerted effort will present a better understanding of the relationship between personality and second language learning.

Sharp (2008) examined the relationships which exist between personality and second language learning. This study was carried on 100 Hong Kong university undergraduates. The instruments used were the MBTI for personality traits, the Strategy Inventory for Language Learning (SILL) for learning strategies and a standardized test for language proficiency. The 
research emphasized the importance of personality in learning success discussing some of the inconsistent results that have been obtained. The findings of the study concluded that no significant statistical relationships were found providing some explanations.

Kayaoğlu (2013) investigated whether or not there is any correlation between extroversion and introversion and language-learning strategies. Participants in the study were 106 extroverted and 94 introverted students. The Eysenck Personality Questionnaire (EPQ) and the Strategy Inventory for Second Language Learning (SILL) were employed. The findings indicated that, with the exception of communicative strategies, introverted learners used a greater range of metacognitive and cognitive strategies than did extroverted learners.

Khatib and Zuhair (2013) investigated the patterns of English Language learning strategies used by 190 Emirati EFL university students, and examined the effects of gender and proficiency level on the use of these strategies. Data was collected through administering an Arabic translation of Oxford's (1990) Strategy Inventory for Language Learning (SILL) and a demographic questionnaire. The study showed that EFL University students were medium range strategy users and that students favored using metacognitive strategies, followed by social, compensation, affective, cognitive and memory strategies, respectively. Furthermore, gender and language proficiency levels had no significant effects on strategy use of Emirati EFL university learners, nor did they affect any of the six strategy categories.

Moreover, related to compensation strategies, Rokni and Niknaqsh (2013) said that clues can be regarded as a working factor in the way that a learner comprehends a reading passage and context clues can greatly influences reading comprehension of EFL learners.

Alhaysony (2017) examines the strategies 85 Saudi EFL students utilize to understand idioms. Two data collection instruments, questionnaire, semi-structured interview were employed as well as the Nation's Vocabulary Level Test to measure the students' language proficiency level. The findings revealed that most frequently used strategies were guessing the meaning of idioms from context, predicting the meaning of idioms, and figuring out an idiom from an equivalent one in their mother language.

To conclude, the focus of most SILL research was on the strategy use patterns (Khatib \& Zuhair 2013; Raizi, 2007; Alhaysony, 2017) or on other individual difference in relation to SILL such as gender, proficiency (Khatib \& Zuhair 2013). The focus on personality as a factor influencing language learning strategy use was scarce. Some studies concentrated on one personality category e.g. extraversion vs. introversion (Kayaoğlu, 2013) or use different personality parameters such as five-factor model of personality (Niknaqsh, \& Rokni, 2014). The common link among these studies is that there is a significant relationship between the predominant personality trait and language learning strategies of the respondents that is worth investigating. After further inspection on the literature, there were studies which use both SILL and MBTI as research instruments in order to investigate the relationship between language learning strategies and personality types and have achieved significant results (Chen, 2005; Peal, 1994; Shirley, 2007; Sharp, 2008). However, none of these studies were conducted on Arabic speaking students. Therefore, this research is an attempt to bridge this gap by conducting the study on Arabic EFL students in hope of raising the awareness of 
personality as a significant factor on the language learning process in Saudi Arabia.

\section{Methodology}

\subsection{Participants and Sampling}

The sample was drawn from a population of Saudi University EFL female students, mainly English Department students of IMSIU. The researcher randomly selected 68 female English, last-level students. Participants were informed about the study, understood its purpose, and had the right to refuse participating at any time. Each participant filled out two instruments. The instruments were administered online ensuring comfortably and convenience for participants. The MBTI test took about 15 minutes to administer, and the SILL test took an average of 10 minutes. These time averages were provided by the survey service online.

\subsection{Instrumentation}

The data was collected using two separate instruments: an abridged version of the Myers-Briggs Type Indicator (MBTI), and the Strategy Inventory for Language Learning. The participants who agreed to participate in this study completed all two instruments. Subjects who completed only one instrument were excluded.

\subsubsection{The MBTI}

The Myers-Briggs Type Indicator (MBTI) is a self-report questionnaire that outlines personality preferences in the form of four different categories which include: ExtroversionIntroversion, Sensing-Intuition, Thinking-Feeling, and Judging-Perceiving. The original MBTI is a lengthy test which might discourage many students from participation, not to mention if it is conducted along with other tests such as the SILL. Therefore, the abridged online version which contains 60 items was used instead. The creditability of the results is still maintained.

\subsubsection{The SILL}

The Strategy Inventory for Language Learning (SILL) is a "Likert-scaled, self-report instrument which assesses the frequency with which the respondent uses a variety of different techniques for second or foreign language learning" (Oxford \&Ehrman, 1989:23-4). It is the most widely used language learning strategy-assessment instrument in the research and application (Green \& Oxford, 1995). It also has well-documented reliability and validity (Oxford \& Burry-Stock, 1995). The SILL has two forms: a 50-item questionnaire for people learning English as a second or foreign language and an 80-item questionnaire for native English speakers learning other languages. This study uses the first form as it is concerned with EFL learners. The SILL tests strategy preference based on Oxford's classification that consists of six strategy types: memory strategies, cognitive strategies, compensation strategies, metacognitive strategies, affective strategies, and social strategies. 


\subsection{Data Collection}

Sixty eight participants were selected from level eight, English major female students in IMSIU. The researcher explained the aim of the study and procedures for the students as the researcher was looking for participants. Data was collected in an online questionnaire form in the academic year 2016-2017. Prior to completing the survey, there were instructions on how to complete the survey. It was indicated that the activity was not a test; there were no right or wrong answers. Participants were not required to identify themselves in the study. The data collection for the study proceeded in two phases. The participants were asked to take the MBTI test to determine personality type. The test was online and calculates the results immediately. After the participants finish the MBTI test, they were asked to take the SILL administered by the researcher, where they input their MBTI results, personal information, and answer the 50 items of SILL.

\subsection{Data Analysis}

The study employed quantitative methods to analyze the data. The data collected was coded and analyzed using SPSS Statistical Data analysis mainly included descriptive statistics. Descriptive statistics included analysis of means and standard deviations. The study reflects the most and least commonly used strategies by each personality type and the overall strategy pattern in each of the six categories of SILL. The mean scores in this research were interpreted according to Oxford \& Burry-Stock (1995), the range between 1.0 to 2.4 indicates low use of strategy, the range between 2.5 to 3.4 indicates medium use, and high use for the range between 3.5 to 5.0 .

\section{Results}

The main purpose of the study was to investigate the correlation between Saudi Female English major students' personality types and their language learning strategies. The total number of subjects included 68 participants. Two instruments were employed in this study. It included Myers-Briggs Type Indicator (MBTI) and Strategy Inventory for Language Learning. All participants are native speakers of Arabic who study English in university as their second language. The study sought to investigate the following research questions:

1. What is the general pattern of English language learning strategies used by Saudi EFL students?

2. Is there any significant relationship between Saudi EFL students' language learning strategies and their personality types?

\subsection{General Pattern of Language Learning Strategies Used by Saudi EFL Students}

Table 1 shows the means and standard deviations for the Strategy Inventory for Language Learning (SILL) by all participants. The means represent the participants' use of Oxford's language learning strategies to assist their language learning. 


\section{Mll Macrothink}

Table 1. Mean Scores of the SILL for All Participants $(\mathrm{N}=68)$

\begin{tabular}{lcccc}
\multicolumn{1}{r}{ Variable } & $\underline{\text { Mean }}$ & $\underline{\underline{\text { Std. D }}}$ & $\underline{\text { Use }}$ & $\underline{\text { Rank }}$ \\
\hline Memory Strategies & 3.08 & 1.370 & $\mathrm{M}$ & 5 \\
Cognitive Strategies & 3.59 & 1.254 & $\mathrm{H}$ & 2 \\
Compensation Strategies & 3.55 & 1.276 & $\mathrm{H}$ & 3 \\
Metacognitive Strategies & 3.80 & 1.177 & $\mathrm{H}$ & 1 \\
Affective Strategies & 2.87 & 1.451 & $\mathrm{M}$ & 6 \\
Social Strategies & 3.39 & 1.331 & $\mathrm{M}$ & 4 \\
\hline \multicolumn{1}{c}{ ALL } & 3.38 & 1.336 & $\mathrm{M}$ & -
\end{tabular}

Table 1 shows that the average strategy use ranged between high 3.80 to a medium of 2.87, while the overall mean for the sample was 3.38 , which was medium use in comparison to the maximum possible score (5.0) of the SILL. The most frequently used strategy category among the six categories is metacognitive strategies $(\mathrm{M}=3.80)$ followed by cognitive strategies $(M=3.59)$, compensation strategies $(M=3.55)$, social strategies $(M=3.39)$, memory strategies $(M=3.08)$, and finally, affective strategies $(M=2.87)$. Therefore, the individual use for each strategy category is as follows; medium use for social, affective and memory strategies, and high use for metacognitive, cognitive and compensatory strategies. Correlation between Saudi EFL students' language learning strategies and their personality types

\subsection{The Correlation between Students Language Learning Strategies and Their Personality Types}

This study examined whether a significant relationship existed among Saudi EFL university students' English learning strategy use based on their personality type. Personality type distributions are shown in Table 2. It includes 68 individuals. Three participants were excluded due to unclear MBTI scores.

Table 2. Personality type distribution of the research sample $\mathrm{N}=68$

\begin{tabular}{|l|l|l|l|}
\hline ISTJ & ISFJ & INFJ & INTJ \\
$\mathrm{N}=5$ & $\mathrm{~N}=8$ & $\mathrm{~N}=3$ & $\mathrm{~N}=5$ \\
\hline ISTP & ISFP & INFP & INTP \\
$\mathrm{N}=2$ & $\mathrm{~N}=6$ & $\mathrm{~N}=0$ & $\mathrm{~N}=6$ \\
\hline ESTP & ESFP & ENFP & ENTP \\
$\mathrm{N}=5$ & $\mathrm{~N}=3$ & $\mathrm{~N}=5$ & $\mathrm{~N}=2$ \\
\hline ESTJ & ESFJ & ENTJ & ENFJ \\
$\mathrm{N}=5$ & $\mathrm{~N}=7$ & $\mathrm{~N}=3$ & $\mathrm{~N}=3$ \\
\hline
\end{tabular}

Note. $\mathrm{I}=$ Introvert, $\mathrm{E}=$ Extrovert, $\mathrm{S}=$ Sensing, $\mathrm{N}=$ Intuitive, $\mathrm{F}=$ Feeling, $\mathrm{T}=$ Thinking, $\mathrm{J}=$ Judging, $\mathrm{P}=$ perceiving 


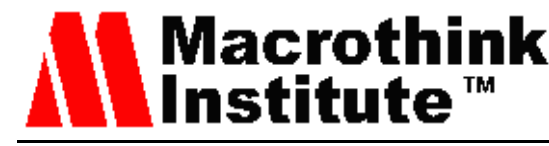

The number of participants representing the sixteen personality types was too small to provide significant results. Therefore, the eight major types (four dichotomies) were used for statistical analysis. Descriptive statistics were conducted for the eight inventories of MBTI (E, I, S, N, T, F, J and P) in table 3.

Table 3. Personality inventories used in data analysis

\begin{tabular}{llll}
\hline $\mathrm{E}=33$ & $\mathrm{~S}=41$ & $\mathrm{~T}=33$ & $\mathrm{~J}=39$ \\
$\mathrm{I}=35$ & $\mathrm{~N}=27$ & $\mathrm{~F}=35$ & $\mathrm{P}=29$ \\
\hline
\end{tabular}

Note. $\mathrm{I}=$ Introvert, $\mathrm{E}=$ Extrovert, $\mathrm{S}=$ Sensing, $\mathrm{N}=$ Intuitive, $\mathrm{F}=$ Feeling, $\mathrm{T}=$ Thinking, $\mathrm{J}=$ Judging, $\mathrm{P}=$ perceiving

The data showed the students' slight preference of Introversion over Extroversion, and an evident preference of the Sensing type over Intuitive, which is consistent with Peal's results (1998). Thinkers and feelers were similar in number with a slight preference of the feeling type. This is an unexpected result in the view of Ehrman and Oxford (1989) as they asserted that people involved in language are intuitive thinkers. However, the difference was slight and Peal's results (1998) recorded a similar result. The preference of Judging in the data over Perception was in accordance with Peal's (1998) results. This might be due to the fact that both research the populations of both studies were specialized in language learning. The sample of Peal's research was part of the Summer Institute of Linguistics (SIL).

To explore the relationship between each personality type and preferred English learning strategies according to Oxford's taxonomy, descriptive analysis was applied to each of the eight inventories to find the means of each strategy according to personality type as shown in table 4. If the strategy scores a mean of 5-3.5, it is considered high usage, 3.4-2.5, medium usage, and 2.4-0 low usage.

Table 4. Summary of strategy use by personality type

\begin{tabular}{c|cccccc|c} 
Type & Memory & Cognitive & $\begin{array}{c}\text { Compe } \\
\text { nsation }\end{array}$ & $\begin{array}{c}\text { Meta-cog } \\
\text { nitive }\end{array}$ & Affective & Social & ALL \\
\hline I & 3.14 & 3.51 & 3.49 & 3.83 & 2.86 & 3.34 & 3.36 \\
E & 3 & 3.66 & 3.62 & 3.80 & 2.84 & 3.43 & 3.39 \\
S & 2.97 & 3.42 & 3.41 & 3.66 & 2.80 & 3.32 & 3.26 \\
N & 3.24 & 3.83 & 3.76 & 4.00 & 2.93 & 3.49 & 3.54 \\
F & 2.97 & 3.45 & 3.58 & 3.73 & 2.73 & 3.31 & 3.29 \\
T & 3.19 & 3.73 & 3.53 & 3.87 & 2.98 & 3.46 & 3.46 \\
J & 3.04 & 3.57 & 3.47 & 3.78 & 2.79 & 3.48 & 3.35 \\
P & 3.12 & 3.61 & 3.67 & 3.81 & 2.94 & 3.26 & 3.40
\end{tabular}

Note. $\mathrm{I}=$ Introvert, $\mathrm{E}=$ Extrovert, $\mathrm{S}=$ Sensing, $\mathrm{N}=$ Intuitive, $\mathrm{F}=$ Feeling, $\mathrm{T}=$ Thinking, $\mathrm{J}=$ Judging, $\mathrm{P}=$ perceiving 


\section{Macrothink}

The results indicated a medium use for all strategy categories across all personality types with the exception of the intuitive category which scored an overall high use for all strategies as displayed in Figure 2.

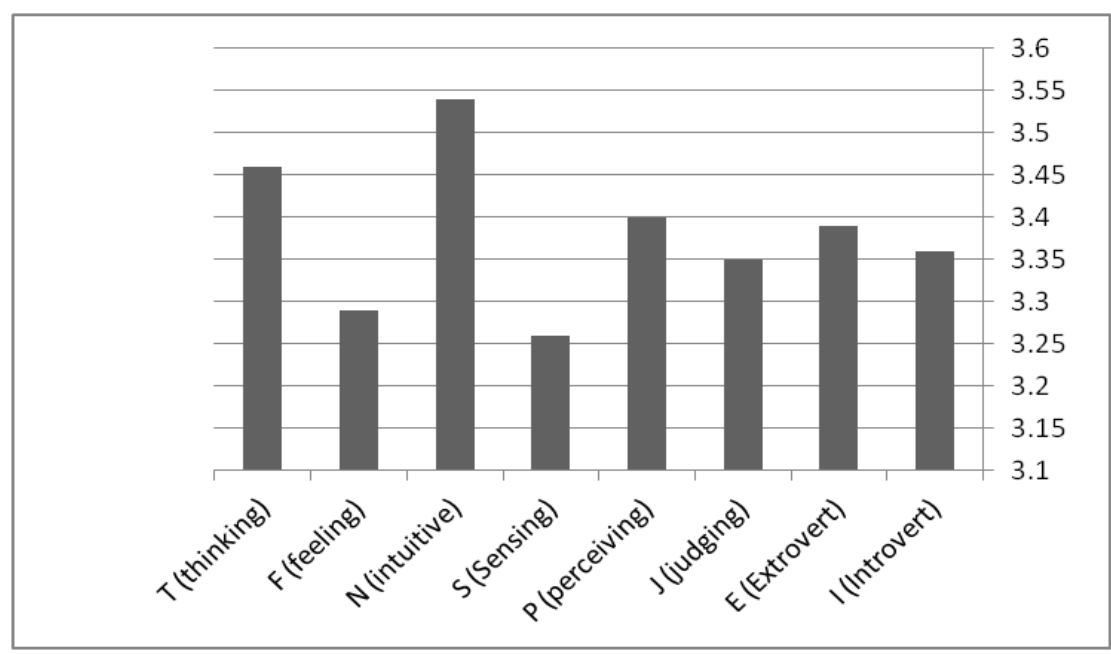

Figure 1. Overall Mean of Strategy use According to Personality Types

Figure 3 illustrates that the strategies frequently used by the Introvert/Extrovert subjects were metacogntive strategies with an average of 3.83 and 3.80, respectively. Both personality types favor the strategies in the following order: metacogntive, cognitive, compensation, social, memory and affective strategies. However, according to the data, extroverts are more likely than Introverts to employ cognitive strategies, compensation and social strategies. For the Introvert category, they are more likely to use memory strategies, metacognitive strategies and affective strategies than extroverts although the means were not that much different in metacognitive strategies and affective strategies recording a 0.03 difference for metacogivntive strategies and 0.02 difference for affective strategies. Affective strategies were found to be the least popular of all strategies, with an average of 2.86 and 2.84 .

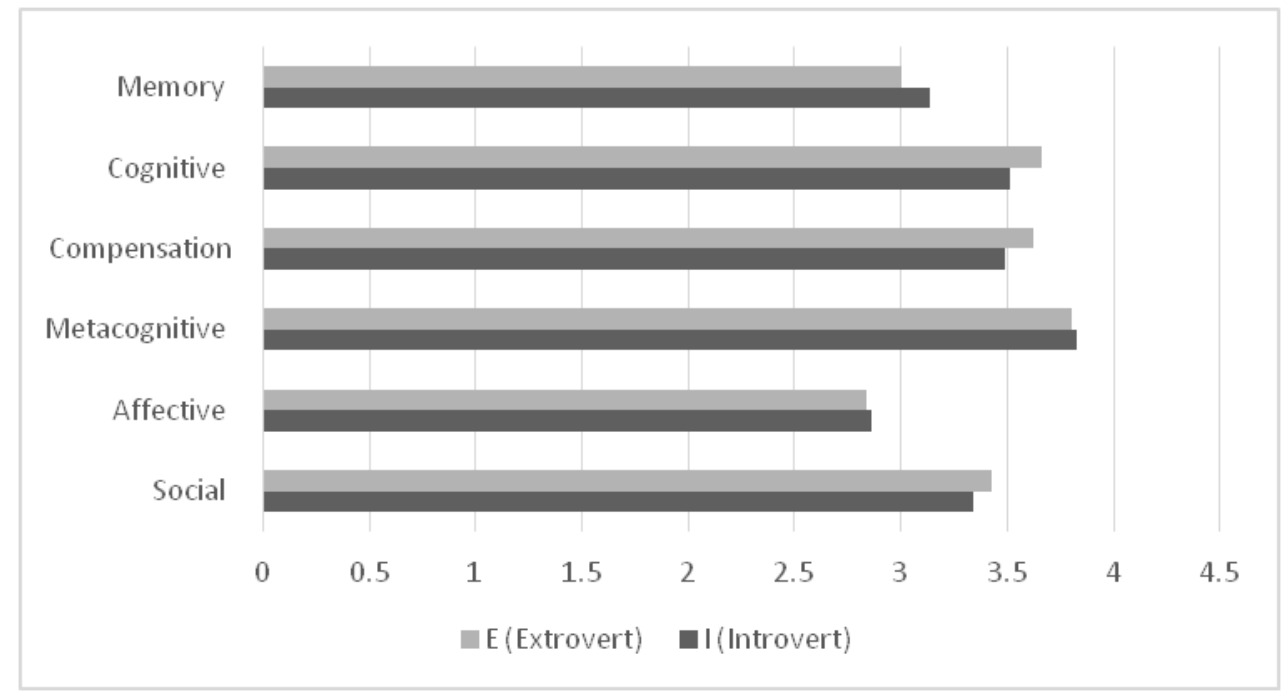

Figure 2. Mean scores of language learning strategies by Introvert/Extrovert personality type 


\section{Macrothink}

The present study indicates that extrovert learners reflect a slight preference of language learning strategy use with an overall mean of 3.39 compared to introvert learners (3.36). In Ehrman and Oxford's $(1989,1990)$ study, Extroverts reported significantly greater use of affective strategies and social strategies than Introverts. However, this study did not follow the same pattern for affective strategies. To sum up, extroverts and introverts prefer the same strategies with minor differences in some. The metacognitive strategies are the most preferred while affective strategies are the least popular.

Intuitive learners, in this study, used all English learning strategies more often than Sensing learners. This finding is consistent with Ehrman and Oxford's (1989), and Chen's (2005) findings. Mean scores for the SILL among Intuition/Sensing category students are reported in Table 10 and represented in Figure 4.

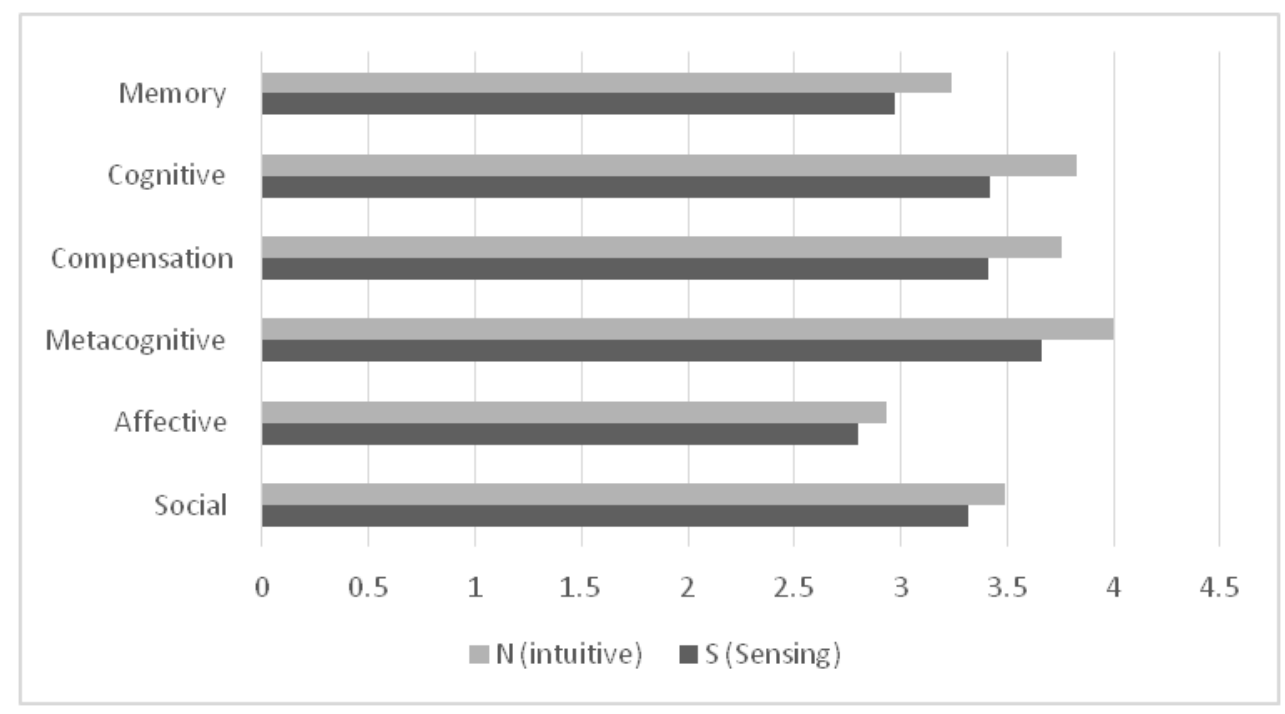

Figure 3. Mean scores of language learning strategies by Intuition/Sensing personality type

Figure 4 shows that the most frequently-used strategies by participants in the Intuition/Sensing category was metacogntive strategies with an average of 4.00 and 3.66, respectively. Affective strategies, were reported to be the least popular of all strategies with an average of 2.93 (Intuition type) and 2.80 (Sensing type). The present study found some support in the findings of previous studies (e.g., Ehrman \& Oxford, 1989, 1990; \& Chen, 2005), in which Intuition types have displayed greater use of compensation strategies compared to all personality types. Ehrman and Oxford $(1989,1990)$, also reported that Sensing individuals employ memory strategies more frequently than Intuition types. However, this study failed to produce the similar results. Instead, the data shows that Sensing learners do not favor memory strategies. This is contrary to previous study, but in favor of Chen's (2005) study in which intuitive learners preferred memory strategies. 


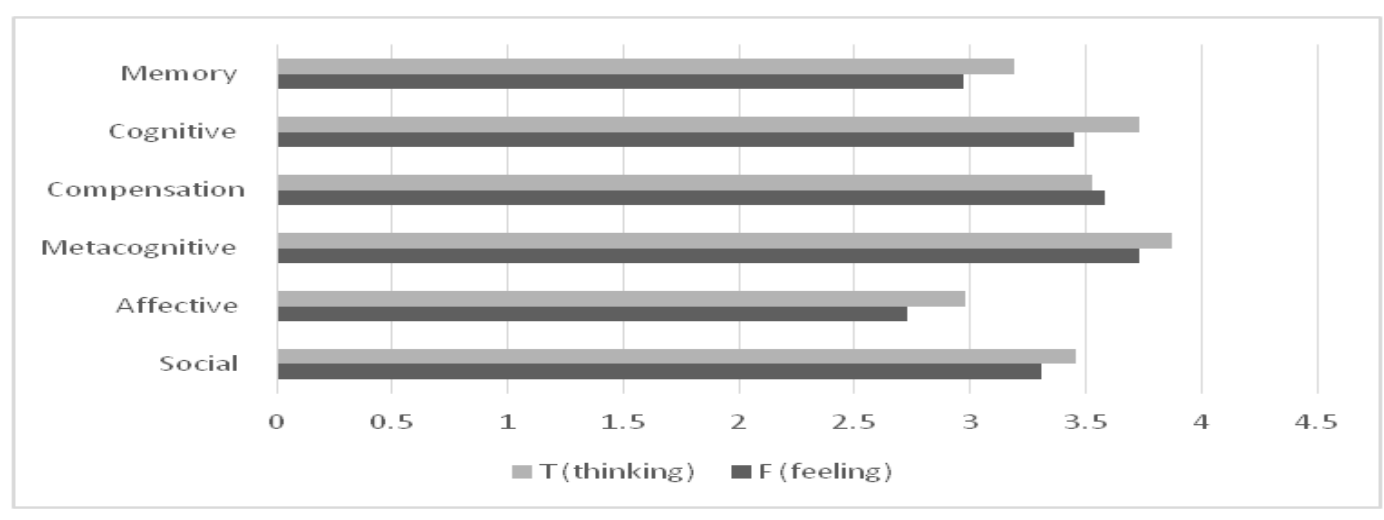

Figure 4. Mean scores of language learning strategies by Feeling/Thinking personality type

The present study found that Feeling/Thinking type learners show greater use of metacogntive strategies according to the data presented in Table 10 and represented in Figure 5 above. Thinkers reported greater use of all strategies than Feelers with the exception of compensation strategies. The results were consistent with Ehrman and Oxford (1989) study that found Thinkers' evident preference of cognitive strategies compared to Feelers. Like all personality types in this study Metacogntive strategies are the most frequently used by the participants with an average of 3.73 (Feeling Type) and 3.87 (Thinking Type). Affective strategies were found to be the least popular of all strategies with an average of 2.73 (Feeling Type) and 2.98 (Thinking Type). However, thinkers scored the highest out of all other personality types for Affective strategies.

Figure 6 demonstrates Judging/Perceiving personality type mean scores. Learners in the Judging/Perceiving category identified metacognitive strategies as the most frequently used strategies, with averages of 3.78 and 3.81, respectively. As indicated in Figure 6, affective strategies were reported to be the least popular of all strategies with an average of 2.79 (Judging) and2.94 (Perceiving). The Judging/Perceiving category in this study display similar characteristics with previous studies. Judging students in Ehrman and Oxford's (1990) study, preferred metacognitive strategies like "tactical" planning, as well as social strategies. On the other hand, Perceiving learners use compensation strategies more frequently than Judging students. Thus, Perceivers use strategies concerned with communicating meaning and searching to fill linguistic gaps when information is limited (Ehrman \& Oxford, 1989).Overall, analysis of the above data reveals that a significant relationship exists among Saudi EFL university students' language learning strategies and their personality types. 


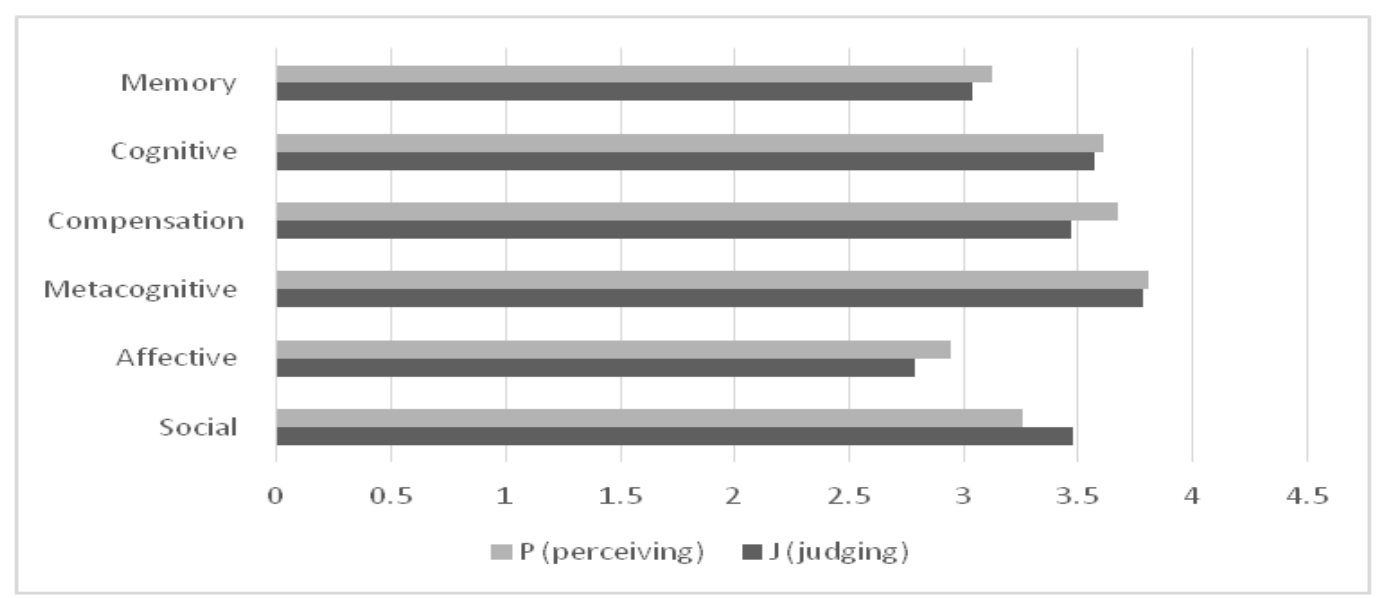

Figure 5. Mean scores of language learning strategies by Judging/Perceiving personality type

\section{Discussion}

This section concludes the research by presenting and discussing the results. The findings of the study are discussed and interpreted. Implications of this research on the process of language learning are presented. Recommendations for further research end the chapter.

\subsection{Overall Language Learning Strategy Use}

This study came to a conclusion that EFL learners at Saudi Universities in Riyadh scored borderline medium to high strategy use with an overall strategy mean of 3.38 out of 5.0. An interesting comparison of these findings can be made to other studies. These results were consistent with the findings of some previous research conducted on Arab EFL learners. Khatib \& Zuhair (2013) examined the frequency of English language learning strategies use in Arabic-speaking EFL students at the University General Requirements Unit in UAE. The results showed that the participants were medium strategy users in general. Another compatible result is McMullen's study (2009) which investigated language learning strategies use of Saudi EFL students in three Saudi universities. The findings showed that the overall strategy use of students was within the medium range. Khalil (2005) investigated the assessment of language learning strategies used by Palestinian EFL learners. He conducted his study on both high school and university students, the overall strategy use for both groups fell within the medium range. There are studies conducted on non-Arabs which have compliable findings. On the other hand, there are some findings in the literature that reported high range of overall use of language learning strategies. For example, Yilmaz's study (2010) which investigated English language learning strategies use of English major students enrolled at a university in Turkey. The findings revealed that the participants were overall high strategy users. This might be considered inconsistent with this study; however, Yilmaz's mean was borderline high at 3.54, which indicates a minor difference of 0.16 between the two studies.

The findings of this study indicated that the students used the six strategy categories with a mean that ranged between 3.08 - 3.80. Metacognitive strategies were the most frequently used followed by cognitive strategies, compensation strategies, social strategies, memory strategies, 
and affective strategies; which were the least frequently used among the six categories. This ranking of strategies is consistent with various studies conducted on Arab students (Abu Shamis, 2003; Riazi, 2007; Al-Buainain, 2010, Abu Radwan, 2011; Alhaysony, 2017). Abu Shamis (2003) investigated language learning strategy use in Palestine. The results of strategyuse according to university average of more proficient students indicated a similar preference to the current study. Riazi (2007) investigated the patterns of language learning strategy use among female Arabic-speaking students majoring in English at a university in Qatar using Oxford's (1990) SILL. The results were consistent with the findings of this study as it showed that the most highly used strategies by these students were metacognitive strategies. Al-Buainain (2010) examined Language Learning Strategies Employed by English Majors at Qatar University. The findings of the study were strikingly similar to the current research. The means and percentages for Al-Buainain's study showed that metacognitive strategies had the highest percentage followed by cognitive, compensation and social, while both memory and affective strategies ranked the lowest. Abu Radwan (2011) investigated the effects of second language proficiency and gender on choice of language learning strategies by university students majoring in English in Sultan Qaboos University in Oman. The research findings indicate that students use metacognitive strategies significantly more than any other category of strategies, and memory strategies reported the least used strategies by participants. Alhaysony (2017) investigated language learning strategies (LLS) used by Saudi EFL students at Aljouf University. The results showed that the average of strategy use was in the low to medium range. Cognitive, metacognitive and compensation strategies were used most frequently, while memory and affective strategies were reported to be least frequently used.

It can be concluded that Saudi EFL University students use metacognitive strategies most $(M=$ 3.80). In addition to previous studies which were consistent with the finding of the study as a whole, Khatib\&Zuhair (2013) presented a similar result where metacognitive strategies were the most favorite among UAE learners. Metacognitive strategies "make use of knowledge about cognitive processes and constitute an attempt to regulate language learning" (Ellis, 1994, p. 538). Such strategies are used to manage overall learning process identifying one's needs and preferences, planning for a language task, setting goals and objectives, and evaluating task success (Ehrman, Leaver, \& Oxford, 2003). Metacognitive strategies also play a major role in helping the learners understand their own cognition and the way they learn by organizing, monitoring and evaluating their language learning process. In sum, it is concerned with self-monitoring and self-evaluating.

The second most preferred strategy was Cognitive Strategies $(M=3.59)$. Cognitive Strategies are conscious methods that enable the learner to manipulate or handle the target language in direct ways. These strategies focus on developing thinking skills and producing new language through practicing, summarizing, reasoning, guessing, and analyzing and analyzing and reasoning (Oxford, 1990; Ehrman, Leaver, \& Oxford, 2003). This is inconsistent with research findings on other Arab EFL learners (Chen, 2005; McMullen, 2009; Khalil, 2005, Y1lmaz, 2010). However, looking at the participants of this study, this preference is not surprising. Metacognitive and cognitive strategies are essential for English major students as they are considerably conscious about their language learning process more than common learners who 
participate in a language course for pleasure, academic or professional advancement or because the University requires it (Al-Bunanin, 2010). Thus, students majoring in English think a lot about their progress and their language learning process in order to insure they are successful. Khatib \& Zuhair (2013) added another possible explanation that cognitive strategies are significantly related to English proficiency. As most of the current sample are graduate/post graduate students, it is presumed that they are of higher proficiency. These findings are also consistent with that of O'Malley, et al. (1985) where the study reported regular use of metacognitive and cognitive strategies by second language learners. This finding also corresponds to that of Oxford (1990), who suggests that cognitive strategies are the most popular strategies among language learners.

Compensation strategies ranked the third most used strategies $(M=3.55)$. These strategies enable language learners to overcome any limitations or gaps in their linguistic knowledge. Means and standard deviations showed high to medium use of strategies with the exception of one strategy, which indicated a low use. The three first strategies were reported to be frequently used by Arab English major students, such findings are supported in other studies (e.g. Abu Shamis, 2003; Abu Radwan, 2011; Riazi, 2007; Al-Buainain, 2010; Alhaysony, 2017).

Social strategies were ranked fourth with $(M=3.39)$. Social strategies are strategies for learning through interaction with others and for understanding the new language culture, e.g., through questioning, asking for help, asking for clarification, talking with a native-speaking conversation partner and cooperating with peers (Oxford \& Ehrman, 1990; Ehrman, Leaver, \& Oxford, 2003). Learning a language involves the target culture and social norms as well as other people and it is extremely important that learners employ appropriate social strategies in this process (Oxford, 1990). These findings are consistent with those in the literature (e.g.Abu Shamis, 2003; Abu Radwan, 2011; Riazi, 2007; Al-Buainain, 2010; Alhaysony, 2017).

The least favored strategies by participants in this study were memory strategies and affective strategies. Memory strategies were ranked fifth $(M=3.08)$ and affective strategies were the least favorite strategies in this study $(M=2.87)$. Although are the least favored, both were of medium use. Memory strategies help learners store and retrieve new information (Oxford \& Ehrman, 1990). They help learners create links between language items or concept with other concepts or images and sounds but do not necessarily require profound understanding (Ehrman, Leaver, \& Oxford, 2003). The common assumption that EFL students frequently use memory strategies especially in an didactic instructional system like the one found in Arab countries has been contradicted by further examination of the literature. Other studies also had contradictory findings (e.g. Al-Bunaian, 2010, Alhaysony, 2017; Al-Otaibi, 2004).

Affective strategies are strategies that enable learners to manage their own emotions, attitudes, motivations, and values associated with language learning (Oxford \&Ehrman, 1990). They can be achieved by techniques like self-encouragement or self-rewards and deep breathing to lower anxiety which help learners gain better control over emotional temperature related to language learning (Oxford \&Crookall, 1989). This is consistent with Abu Shamis (2003), Al-Buainain (2010) and Alhaysony (2017) research. Alhaysony (2017) argues that the low use of affective might be due to the lack of interactions with native speakers outside the 
classroom. Another possible explanation is Abu Shamis's (2003) findings that indicated that less proficient students use affective and "Others" strategies more frequently in order to lower their anxiety, and encourage themselves to store and retrieve information. Assuming that the sample of this study is of higher proficiency, this explanation is plausible. If perhaps learners' use of cognitive, metacognitive, and social strategies is related to greater proficiency and self-efficacy, over time there might be less need for affective strategies as learners progress to higher proficiency (Al-Buainain, 2010; Al-Otaib, 2004; Chang, 2011; Chen, 2005; Griffiths, 2003; Oh, 1992; Oxford, 1990; Yang, 1993, 2007).

\subsection{The Correlation between Personality and Language Learning Strategies}

The observations indicate that there were significant differences among students' language learning strategy preferences based on their personality type. The results showed a medium use for all strategy categories across all personality types with the exception of the intuitive category which scored an overall high use for all strategies. Metacogntive strategies were the most popular strategies used by all personality types. Affective strategies were found to be the least popular of all strategies across all personality types. There were subtle differences and preferences evident in the four personality dichotomies. Extroverts are more likely than introverts to employ cognitive strategies, compensation and social strategies while introverts are more likely to use memory strategies, metacognitive strategies and affective strategies than extraverts. The present study indicates that extrovert learners reflect a slight preference of language learning strategy use compared to their introvert counterparts. The results are generally consistent with those reported by Ehrman and Oxford's (1989) study. In both Ehrman and Oxford and the present study, those with an extroverted personality type were more likely than introverts to use social strategies.

Intuitive learners used all English learning strategies more often than Sensing learners. This resultis supported by the findings of previous studies (e.g., Ehrman\& Oxford, 1989, 1990; Chen, 2005), in which intuition types have displayed greater use of compensation strategies compared to all personality types. Ehrman and Oxford (1989\&1990), also reported that sensing individuals employ memory strategies more frequently than intuition types. However, this study failed to produce similar results. Instead, the data shows that sensing learners do not favor memory strategies. This is contrary to the previous studies, but in favor of Chen's (2005) study in which intuitive learners preferred memory strategies instead of sensing learners. Intuitive learners high use of strategies can be attributed to their tendency to process information through patterns and impressions.

Thinkers reported greater use of all strategies than feelers with the exception of compensation strategies. The results were consistent with Ehrman and Oxford (1989) study that found thinkers' evident preference of cognitive strategies compared to feelers. Thinkers scored the highest out of all other personality types for affective strategies. This is because thinkers are more rational and more likely to manage their own emotions, attitudes, motivations, and values associated with language learning. The judging/perceiving category displayed a similar result with previous studies. Judging students in Ehrman and Oxford 's (1990) study, preferred metacognitive strategies like "tactical" planning, as well as social strategies. On the 
other hand, Perceiving learners use compensation strategies more frequently than Judging students. Thus, Perceivers use strategies concerned with communicating meaning and searching to fill linguistic gaps when information is limited (Ehrman\& Oxford, 1989). Overall, based on the results, it is likely that a relationship exists between language learning strategies and personality types (Ehrman\& Oxford, 1989, 1990; Chen, 2005). However, further research is recommended to account for other variables that may have affected the results, such as gender, aptitude and proficiency level.

\section{Conclusion}

This study investigated the use of language learning strategies among Saudi English Major students in an attempt to provide a deeper understanding of the relationship between personality type and English language learning strategies. It was revealed that all six language-learning strategies were employed at a medium-high use. Overall, the ranking of the preferred strategies is logical and consistent with other research findings. The results revealed that there is a relationship that exists between English major university students' language learning strategies and their personality types. Although there were some indications of personality preferences for some strategies, the relationship between the two variables is more complex and by no means direct. This might be due to the fact that personality itself is a factor affected by other variables. This calls for further research on the topic as suggested in the following recommendations.

\section{Implications}

The findings of this study might reflect a better understanding of the overall strategies used by Saudi English Major University students and its relation to personality type. The outcomes of this study can be utilized by second language learners to select and use more appropriate strategies for language learning. Moreover, it can build awareness of the significance of individual differences, namely personality, among language learners. This can lead them towards more autonomy and a learner centered class. Educators might recognize the role of leaning strategies for language learners, and be aware of the significance of factors such as personality in the learner choice of strategy use. It also provides an opportunity for curriculum planners and syllabi designers to incorporate more strategies in syllabi, textbooks, tasks and activities.

\section{Recommendations for Further Research}

As there are a number of gaps that would benefit from further research, the following recommendations are suggested:

1. The current study only dealt with learning strategies and personality types. However, there are other significant individual differences such as proficiency level, age, and 
achievement learning aptitude, gender, culture, age, and other demographic variables. Further research is recommended to investigate the relationship between these different areas to provide a better understanding of individual differences in second language learning.

2. This research only utilized survey instruments. It is suggested that other studies use qualitative methods such as interviews, journal analysis, classroom observations, and think-aloud in order to illustrate more information about the students' language learning strategies use. Furthermore, combination of both qualitative and quantitative research methods can be considered in future research in order to get a more comprehensive view of the research results.

\section{References}

Al-Buainain, H. (2010). Language learning strategies employed by English Majors at Qatar University: Questions and Queries. ASIATIC, 4(2), 92-120.

Al-Otaibi, G. (2004). Language learning strategy use among Saudi EFL students and its relationship to language proficiency level, gender and motivation. Unpublished $\mathrm{PhD}$ Dissertation, Indiana University of Pennsylvania.

Chen, L. S. (2005). The relationship among perceptual style preferences, language learning strategies and personality types among Taiwan senior high school EFL students.(Doctoral Dissertation). Texas: Texas A-M University. Retrieved from ProQuest Digital Dissertations. (305395564).

Cohen, A. D. (1988). Studying language learning strategies: How do we get the Information? In A. L. Wenden \& J. Rubin (Eds.), Learner strategies in language learning (pp. 31-40). Englewood Cliffs, NJ: Prentice-Hall International.

Cook, V. (2001). Second language learning and language teaching. London: Arnold.

Dornyei, Z. (2005). The psychology of the language learner: Individual differences in second language acquisition. Mahwah, NJ: Lawrence Erlbaum Associates, Inc.

Dollinger, S. J., \& Orf, L. A. (1991). Personality and performance in "personality": Conscientiousness and openness. Journal of Research in Personality, 25, $276-284$.

Ellis, R. (1985). Understanding second language acquisition. Oxford: Oxford University Press.

Ellis, R. (1994). The study of second language acquisition. Oxford: Oxford University Press.

Ehrman, M., Leaver, B., \& Oxford, R. L. (2003). A brief overview of individual differences in second language learning. System, 31, 313-330. 


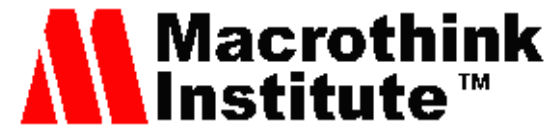

Journal for the Study of English Linguistics

ISSN 2329-7034 2019, Vol. 7, No. 1

Ehrman, M. \& R, Oxford. (1989). Effects of gender differences, career choice, and psychological type on adult language learning strategies. Modern Language Journal, 73(1), $1-13$.

Ehrman, M., \& Oxford, R. (1990). Adult language learning styles and strategies in an intensive training setting. Modern Language Journal, 74, 311-326.

Green, J., \& Oxford, R. (1995).A Closer Look at Learning Strategies, L2 Proficiency, and Gender. TESOL Quarterly, 29(2), 261-297. doi:10.2307/3587625.

Griffiths, C. (2003). Patterns of language learning strategy use. System, 31, 367-383.

Juanito P. TandocJr., \& Ma. Victoria Tandoc - Juan. (2014). Students' Personality Traits and Language Learning Strategies in English. Researchers World. Journal of Arts Science \&Commerce, $3,1-10$.

Kayaoğlu, M. N. (2013). Impact of extroversion and introversion on language-learning behaviors. Social Behavior and Personality, 41(5), 819-825.

Khatib, A., \& Zuhair, A. (2013). Language Learning Strategies of EFL Students in the University General Requirements Unit in the United Arab Emirates University. Theses, 282. Retrieved from http://scholarworks.uaeu.ac.ae/all_theses/282

Liyanage, I., \& Bartlett, B. (2013). Personality types and languages learning strategies: Chameleons changing colours. System, 41, 3, 598-608.

Myers \& Briggs Foundation.(2014). MBTI basics. Retrieved from http://www.myersbriggs.org/my-mbti-personality-type/mbti-basics

Naiman, N. (1978). The Good Language Learner. Toronto. Ontario Institute for Studies in Education.

Niknaqsh, H. R., \&Rokni, S. J. (2014). The Relationship between Personality Traits and Language Learning Strategies of EFL University Students. ELT VOICES, 4(1), 196-204. Retrieved from http://eltvoices.in/Volume4/Issue_1/EVI_41_10_Hamid_Reza_Niknaqsh.pdf

Norton, B., \& Toohey, K. (2001). Changing Perspectives on Good Language Learners. TESOL Quarterly, 35: 307-322. doi: 10.2307/3587650.

Oh, J. (1992). Learning strategies used by university EFL students in Korea. Language Teaching, 1, 3-53.

O'Malley, J. M., \& Chamot, A. (1990). Learning Strategies in Second Language Acquisition. Cambridge: Cambridge University Press.

O’Malley, J. M., Chamot, A. U., Stewner-Manzanares, G., Kupper, L., \& Russo, R. P. (1985) 'Learning strategies used by beginning and intermediate ESL students. Language Learning, 35, $21-46$.

Oxford, R. L. (1990). Language Learning Strategies: What Every Teacher Should Know. Boston, MA: Heinle \& Heinle. 
Oxford, R. L., \& Burry-Stock, J. A. (1995). Assessing the use of language learning strategies worldwide with the ESL/EFL version of the strategy inventory for language learning (SILL). System, 23(1), 1-23.

Oxford, R., \& Crookall, D. (1989). Language learning strategies: methods, findings, and instructional implications'. Modern Language Journal, 73, 404-419.

Peal, L. A. (1994). Second language learning strategies and personality type (Unpublished Ph.D Dissertation: The University of Texas at Arlington) Retrieved from ProQuest Dissertations \& Theses. (AAT 1358881)

Pica, T. (2003). Second language acquisition research and applied linguistics. Working Papers in Educational Linguistics, 18, 112-133.

Riazi, A. (2007). Language learning strategy use: Perceptions of female Arab English majors. Foreign Language Annals, 40(3), 433-440.

Rubin, J. (1975). "What the "Good Language Learner" Can Teach Us". TESOL Quarterly, 9(1), 41-51.

Sharp, A. (2008). Personality and Second Language Learning. Asian Social Science ASS, 4(11). doi:10.5539/ass.v4n11p17.

Shirley, C. L. (2007). Personality and second language learning in a defense program of modern standard Arabic studies. (Doctoral Dissertation). Palo Alto, CA: Consulting Psychologist Press Inc.

Stern, H.H. (1975). Issues and Options in Language Teaching. Oxford: OUP.

Wakamoto, N. (2009). Extroversion/introversion in foreign language learning: Interactions with learner strategy use. Bern: Peter Lang.

Yang, N. (1993). Understanding Chinese students' language beliefs and learning strategy use. Paper presented at the 29th annual meeting of teachers of English to speakers of other languages, Long Beach, California, USA (ERIC Document Reproduction Service No. ED 371589).

Yang, M. (2007). Language learning strategies for college students in Taiwan: Investigating ethnicity and proficiency. Asian EFL Journal, 9(2), 35-57

Y1lmaz, C. (2010). The relationship between language learning strategies, gender, proficiency and self-efficacy beliefs: A study of ELT learners in Turkey. Procedia Social and Behavioral Sciences, 2, 682-687. 


\section{Copyright Disclaimer}

Copyright for this article is retained by the author(s), with first publication rights granted to the journal.

This is an open-access article distributed under the terms and conditions of the Creative Commons Attribution license (http://creativecommons.org/licenses/by/3.0/). 